\title{
RESEARCH
}

Open Access

\section{Prevalence of Schistosoma mansoni infection among children in Ethiopia: a systematic review and meta-analysis}

\author{
Habtye Bisetegn ${ }^{1 *}$, Tegegne Eshetu ${ }^{2}$ and Yonas Erkihun ${ }^{1}$
}

\begin{abstract}
Background: Schistosomiasis is a neglected tropical disease caused by mainly Schistosoma mansoni and Schistosoma hematobium. The disease is very common in Africa including Ethiopia. Schistosoma mansoni is a major public health problem in Ethiopia especially among children. This review is aimed to indicate the prevalence of Schistosoma mansoni among children at the national and regional levels.

Methods and material: The PRISMA guidelines were followed. An electronic search of PubMed, Google Scholar, Web of Science, Scopus, MEDLINE, and Google search were carried out using key terms. Articles published from the proceeding of professional associations such as the Ethiopian medical laboratory association, the Ethiopian public health association, and annual national research conferences were also searched to find additional eligible studies. Data were extracted independently by two investigators, and cross-checked by a third reviewer. The quality of included studies was assessed using JBI quality assessment criteria. Data were extracted using Microsoft excel and finally analyzed using STATA version 12. The pooled prevalence was done using a random-effects model.

Result: Overall 49 studies involving 20,493 children (10,572 male and 9, 921 females) were included in this metaanalysis. The pooled prevalence of Schistosoma mansoni infection was 37.13\% (95\%Cl:30.02-44.24). High heterogeneity was observed with $I^{2}$ of $99.4 \%, P<0.000$. According to subgroup analysis, the pooled prevalence was high in the SNNPR (41.49\%: 95\%Cl: 19.52-63.46) followed by the Amhara region (41.11\%: 95\%Cl: 30.41-51.8), the Tigray region (31.40\%: 95\%Cl:11.72-51.09), and the Oromia region (28.98\%: 95\%Cl: 18.85-39.1). Year from 2011 to 2015 contributed to the highest prevalence of Schistosoma mansoni infection among children (46.31\%: 95\%:34.2159.05).
\end{abstract}

Conclusion: This study revealed a $37.13 \%$ prevalence of Schistosoma mansoni infection among children. This is an alert to improve and implement appropriate control strategies such as mass drug administration in Ethiopia.

Keywords: Schistosomiasis, Schistosoma mansoni, Children and Ethiopia

\footnotetext{
* Correspondence: habtiye21@gmail.com

College of Medicine and Health Sciences, Department of Medical Laboratory Sciences, Wollo University, Dessie, Ethiopia

Full list of author information is available at the end of the article
}

C C The Author(s). 2021 Open Access This article is licensed under a Creative Commons Attribution 4.0 International License, which permits use, sharing, adaptation, distribution and reproduction in any medium or format, as long as you give appropriate credit to the original author(s) and the source, provide a link to the Creative Commons licence, and indicate if changes were made. The images or other third party material in this article are included in the article's Creative Commons licence, unless indicated otherwise in a credit line to the material. If material is not included in the article's Creative Commons licence and your intended use is not permitted by statutory regulation or exceeds the permitted use, you will need to obtain permission directly from the copyright holder. To view a copy of this licence, visit http://creativecommons.org/licenses/by/4.0/ The Creative Commons Public Domain Dedication waiver (http://creativecommons.org/publicdomain/zero/1.0/) applies to the data made available in this article, unless otherwise stated in a credit line to the data. 


\section{Introduction}

Schistosomiasis is a neglected tropical disease caused by blood-dwelling digenetic trematodes of the genus Schistosoma. It affects mainly the poor and marginalized segment of the world [1]. Schistosomiasis affects more than 240 million people and leads to the loss of 70 million disability-adjusted life years globally. About 800 million people are at risk of infection in 78 countries [2]. Schistosomiasis imposes a negative impact on child development, pregnancy outcome, and agricultural productivity [3]. Children are the more risky group with high morbidity and mortality, in addition, the disease results in anemia, malnutrition, decreased aerobic capacity, growth delay, cognitive and memory impairment [4].

Approximately 207 million people required preventive treatment for Schistosomiasis in 2016 worldwide. Different global and national disease monitoring and control initiatives are ongoing to control Schistosomiasis $[5,6]$. These programs are mainly based on mass drug administration (MDA) with praziquantel. Achievement is evaluated base on the successful treatment of $75 \%$ of the school-age children (SAC) [7, 8].

In Ethiopia, Schistosomiasis is a major public health problem caused by Schistosoma mansoni and Schistosoma hematobium with 5.1 million people infected and 37.3 million people being at risk of infection. Of these, 3.4 million, 12.3 million, and 21.6 million are pre-school children, school-aged children, and adults respectively [9, 10]. The pooled prevalence of $S$. mansoni infection in Ethiopia was reported to be $18.7 \%$ (95\%CI: 14.7-23.5) [11]. Another meta-analysis showed the prevalence of $S$. mansoni and $S$. hematobium among school-age children to be $28.78 \%$ (95\% CI: 23.81, 33.74) [12]. The prevalence of S. mansoni among children ranges from 4.9 to $89.9 \%$ [13, 14]. A population-based survey conducted in the Amhara region, Northern Ethiopia involving 15,455 children (6 to 15 years old) reported a $6.9 \%$ regional prevalence of $S$. mansoni [15]. National mapping of soil-transmitted helminths and S. mansoni in Ethiopia assessed the prevalence of soiltransmitted helminths and S. mansoni from 2650 children of 9-14 years old in the Amhara region and found a $2.6 \%$ prevalence of S. mansoni [16].

Different prevalence studies targeting School-age children had been also conducted in different parties of the country. In the Southwest part of Ethiopia; in Mizan-Aman town $44.8 \%$ [17], in Jimma town $28.7 \%$ [18], and Ejaji town in the West Shoa Zone (12.94\%) [19]. In the Northwest part of Ethiopia; Lake Tana 14.3\% [20], Western Tigray 26.3\% [21], Zarima town $37.9 \%$ [22], Mekelle city 23.9\% [23], Waja Timuga 73.9\% [24], rural Bahir Dar 47.2\% [25], Sanja town $82.8 \%$ [26], Haik town 45\% [27], Maksegnit and Enfranz towns 49\% [28], and in the of West port of Ethiopia; Fincha'a sugar estate $53.2 \%$ [29].
In Ethiopia, more than 14 million SAC require MDA [30]. The Federal Ministry of Health (FMOH) of Ethiopia mapped 346 Schistosomiasis endemic districts and implemented MDA through integrated training, drug distribution, mobilization, technical staff involvement, and resource mobilization. In 2016 about 2.5 million SAC were targeted for MDA and 1.86 million were treated, this showed $74.4 \%$ effectiveness of the MDA program [9]. To control and eliminate Schistosomiasis in Ethiopia, providing a national view of the disease prevalence, and identifying endemic areas are highly significant. Indicating the prevalence of Schistosoma mansoni among children at the national and regional level is a valuable asset for designing the type of prevention and control strategy and implementation of the MDA program. It is also important to indicate the endemic areas and to know the current status of Schistosomiasis in children.

\section{Materials and methods \\ Search strategy and selection criteria}

A systematic search of potentially eligible studies was carried out from September 01/2020 to November 31/ 2020 in PubMed, Google Scholar, Web of Science, Scopus, ResearchGate, MEDLINE, and Google. An additional search was made by June 2021. The literature search was carried out using the search term "((prevalence or magnitude or epidemiology) and (Schistosoma mansoni or intestinal schistosomiasis or Schistosomiasis) and (pre-school children or school-age children or children) and (Ethiopia))". Articles published from the proceedings of professional associations such as the Ethiopian Medical Laboratory Association, the Ethiopian Public Health Association, and the annual national research conference were searched. The reference lists of the retrieved studies and reviews were also searched for additional articles.

The included studies were identified after two reviewers independently screened the title, abstract, and the full-text of the articles obtained from the search, and the results were cross-checked by the third reviewer. The final selection was based on the full-text evaluation.

\section{Data extraction and quality assessment}

The outcome variable for this study was the prevalence of $S$. mansoni infection among children of 6 months to 19 years old in Ethiopia. Data were extracted by the two reviewers independently using a Microsoft excel extraction sheet. The sheet contains information including the name of the primary author, year of publication, study design, diagnostic methods, study group, sample size, number of male participants, and number of female participants, number of positive cases, the prevalence of $S$. mansoni, and the region where the study was conducted. 
The quality of each study was evaluated following the Joanna Briggs Institute (JBI) critical appraisal checklist for prevalence studies [31]. Studies were assessed according to the appropriateness of the method used, validity and accuracy of the diagnostic methods, adequacy of the sample size, validity of the sampling procedures, appropriateness of the study design, and the statistical analysis. Each selected study was assessed using 10 quality control items and for each fulfilled item, a score of 1 was given while 0 was given for each of the unfulfilled items. An aggregate of all the scores was generated and converted into an index. Based on the quality indices generated, studies were classified as having low (0.0$0.3)$, moderate $(0.4-0.6)$, or high $(0.7-1.0)$ quality.

\section{Eligibility criteria}

\section{Inclusion criteria}

The reviewers carefully screened the title, abstract, and full text of each published article for its relevance, and eligibility. Original studies reporting the prevalence of $S$. mansoni infection among children in Ethiopia were included in this systematic review and meta-analysis.

\section{Exclusion criteria}

Studies were excluded if they were reported in a language other than English, used inappropriate study design, and non-representative sample size. Studies conducted in a selective population, and not included relevant extractable data were excluded. Case reports, reviews, and studies conducted on adults were also excluded.

\section{Data synthesis and statistical analysis}

The pooled prevalence was calculated by using the Metan commands in STATA version 12. The pooled effect size was presented in the form of a forest plot. To account for the studies variability, the metaanalysis was carried out using the random effect model. The amount of between-studies heterogeneity was quantified using $\mathrm{I}^{2}$ statistics, which describes the

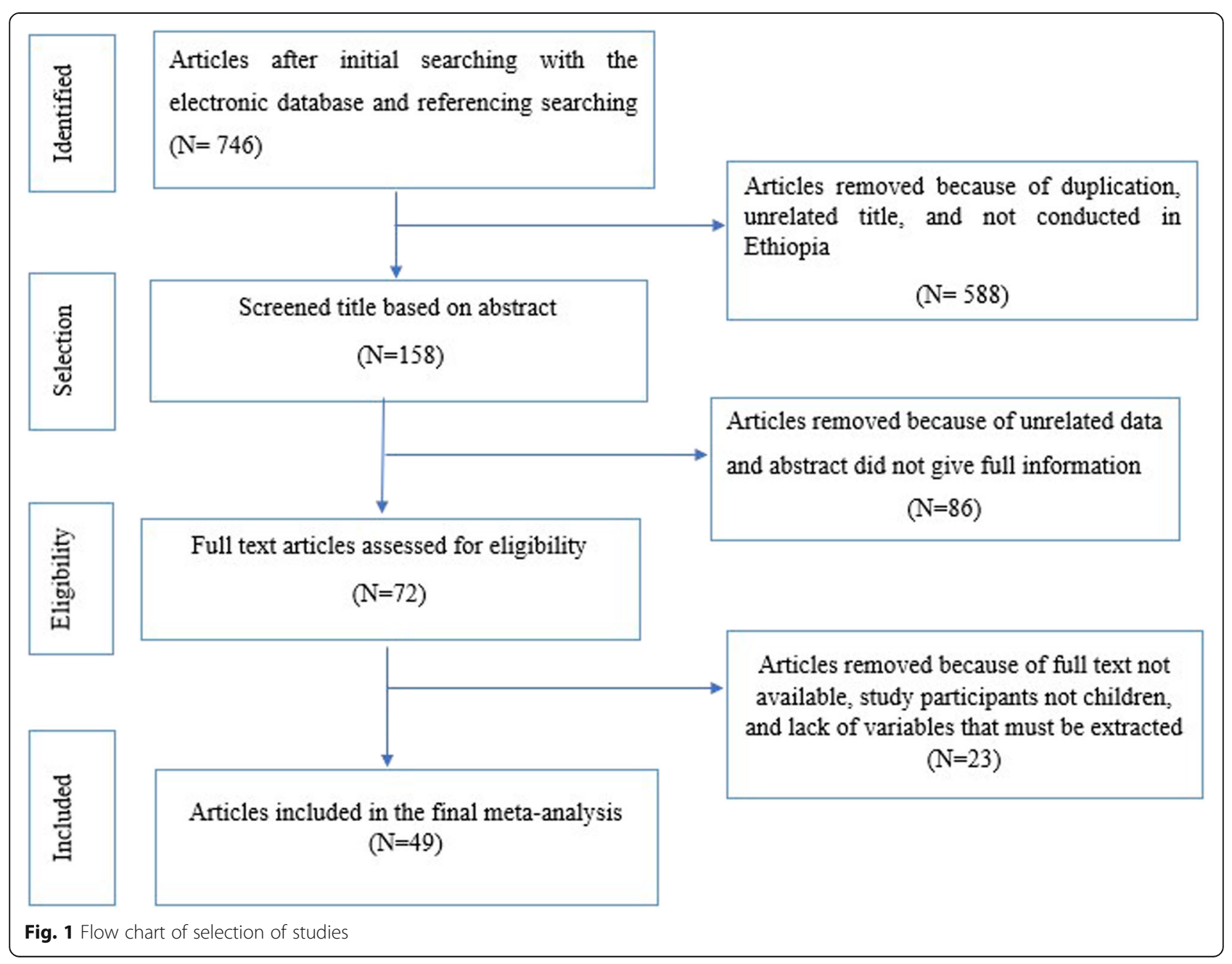


Table 1 Characteristics of included studies

\begin{tabular}{|c|c|c|c|c|c|}
\hline Author/reference & Year & Region & Sample size & Diagnostic methods & Prevalence (\%) \\
\hline Tiruneh A et al [22] & 2020 & SNNPR & 389 & Kato-Katz thick smear & 19.3 \\
\hline Alemu A et al [23] & 2011 & Amhara & 319 & Kato-Katz thick smear & 37.9 \\
\hline Alemu A et al [24] & 2016 & Amhara & 401 & Kato-Katz thick smear & 11.2 \\
\hline Assefa A et al [25] & 2013 & Tigray & 457 & Kato-Katz thick smear & 23.9 \\
\hline Tefera A et al [18] & 2020 & Oromia & 328 & Kato-Katz thick smear & 28.7 \\
\hline Tadege B et al [35] & 2017 & SNNPR & 384 & Kato-Katz thick smear & 31 \\
\hline Alemayehu B et al [36] & 2015 & SNNPR & 384 & Kato-Katz thick smear & 81.3 \\
\hline Alemayehu B et al [37] & 2017 & SNNPR & 503 & Kato-Katz thick smear & 58.6 \\
\hline Mathewos B et al [38] & 2014 & Amhara & 261 & Kato-Katz thick smear & 33.7 \\
\hline Feleke D et al [39] & 2017 & Amhara & 279 & Formol-Ether concentration and direct wet mount & 80.5 \\
\hline Gashaw F et al [28] & 2015 & Amhara & 550 & Kato-Katz thick smear & 49 \\
\hline Amsalu G et al [27] & 2015 & Amhara & 380 & Kato-Katz thick smear & 45 \\
\hline Alebie G et al [26] & 2014 & Amhara & 384 & Kato-Katz thick smear & 82.8 \\
\hline Desta $\mathrm{H}$ et al [40] & 2014 & Tigray & 469 & Kato-Katz thick smear & 42.4 \\
\hline Wubet Ket al [41] & 2020 & Amhara & 362 & Formol-Ether concentration & 15.2 \\
\hline Workineh L et al [42] & 2019 & Amhara & 422 & Kato-Katz thick smear & 24.9 \\
\hline Worku L et al [14] & 2014 & Amhara & 385 & Kato-Katz thick smear and Formol-Ether concentration & 89.9 \\
\hline Alemu $\mathrm{M}$ et al [43] & 2014 & SNNPR & 405 & Kato-Katz thick smear & 12.6 \\
\hline Bajiro M et al [44] & 2017 & Oromia & 500 & Kato-Katz thick smear & 27.6 \\
\hline Bajiro M et al [45] & 2018 & Oromia & 233 & Kato-Katz thick smear & 26.6 \\
\hline Ansha $\mathrm{M}$ et al [46] & 2020 & Oromia & 298 & Kato-Katz thick smear & 11.4 \\
\hline Hailu T et al [25] & 2018 & Amhara & 409 & Ritchie's concentration & 13.7 \\
\hline Ibrahim T et al [19] & 2018 & Oromia & 340 & Kato-Katz thick smear & 12.94 \\
\hline Bekana T et al [47] & 2019 & Oromia & 317 & Kato-Katz thick smear & 42.9 \\
\hline Teshale T et al [13] & 2018 & Tigray & 410 & Kato-Katz thick smear & 4.9 \\
\hline Teklemariam A et al [48] & 2018 & Tigray & 480 & Formol-ether concentration & 23.13 \\
\hline Fentie T et al [49] & 2013 & Amhara & 520 & Kato-Katz thick smear & 16.7 \\
\hline Mitiku $\mathrm{H}$ et al [50] & 2010 & Oromia & 375 & Kato-Katz thick smear & 12 \\
\hline Legesse L et al [51] & 2010 & Tigray & 381 & Kato-Katz thick smear and Formol-Ether concentration & 63 \\
\hline Jemaneh L et al [52] & 2001 & Amhara & 687 & Kato-Katz thick smear & 19.4 \\
\hline Endris M et al [35] & 2010 & Amhara & 354 & Kato-Katz thick smear & 43.5 \\
\hline Essa T el al [36] & 2013 & Amhara & 579 & Kato-Katz thick smear & 20.6 \\
\hline Addisu T et al [37] & 2015 & Amhara & 365 & Kato-Katz thick smear & 15.9 \\
\hline Tulu B et al [53] & 2014 & Oromia & 340 & Formol-Ether concentration & 12.6 \\
\hline Kemal $\mathrm{M}$ et al [39] & 2019 & Somali & 236 & Kato-Katz thick smear & 25 \\
\hline Bajiro M et al [54] & 2016 & Oromia & 500 & Kato-Katz thick smear & 24 \\
\hline Reta B et al [55] & 2013 & Amhara & 342 & Kato-Katz thick smear & 70.47 \\
\hline Erko B et al [56] & 2012 & SNNPR & 299 & Kato-Katz thick smear & 74.9 \\
\hline Haile S et al [43] & 2012 & Oromia & 324 & Kato-Katz thick smear & 67.6 \\
\hline Woldegerima E et al [44] & 2018 & Amhara & 372 & Kato-Katz thick smear & 35 \\
\hline Tesfie A et al [45] & 2020 & Amhara & 245 & Kato-Katz thick smear & 83.3 \\
\hline Abdi M et al [57] & 2016 & Amhara & 408 & Formol-Ether concentration & 29.9 \\
\hline Bekana T et al [58] & 2021 & Amhara & 798 & Kato-Katz thick smear and Formol-Ether concentration & 25.6 \\
\hline Mekonnen Z et al [29] & 2014 & Oromia & 453 & Kato-Katz thick smear & 53.2 \\
\hline
\end{tabular}


Table 1 Characteristics of included studies (Continued)

\begin{tabular}{llllll}
\hline Author/reference & Year & Region & Sample size & Diagnostic methods & Prevalence (\%) \\
\hline Jejaw A et al [17] & 2015 & Amhara & 460 & Kato-Katz thick smear and Formol-Ether concentration & 44.8 \\
Degarege A et al [59] & 2016 & Amhara & 403 & Kato-Katz thick smear and Formol-Ether concentration & 24.6 \\
Degarege A et al [60] & 2014 & Amhara & 620 & Triple urine-CCA-cassette & 81.1 \\
Zeleke A et al [61] & 2020 & Amhara & 786 & Kato-Katz thick smear & 33.5 \\
Shumbej T et al [62] & 2019 & SNNPR & 597 & Kato-Katz thick smear & 12.9 \\
\hline
\end{tabular}

proportion of total variation of the effect estimates resulting from the between-studies heterogeneity and values can be from 0 to $100 \%$. The $\mathrm{I}^{2}$ values of 25 , 50 , and $75 \%$ were considered low, moderate, and high heterogeneity, respectively [32].

The potential influence of the covariates on the pooled effect estimate was investigated by subgroup analysis.
Subgroup analysis was done by the region where the studies were conducted, year of publication, sample size, and sex of study participants. Publication bias was assessed by visual inspection of symmetry of the funnel plot and the egger's test statistics. $P$-value $\leq 0.05$ and asymmetry of the funnel plot indicate the presence of publication bias [33].

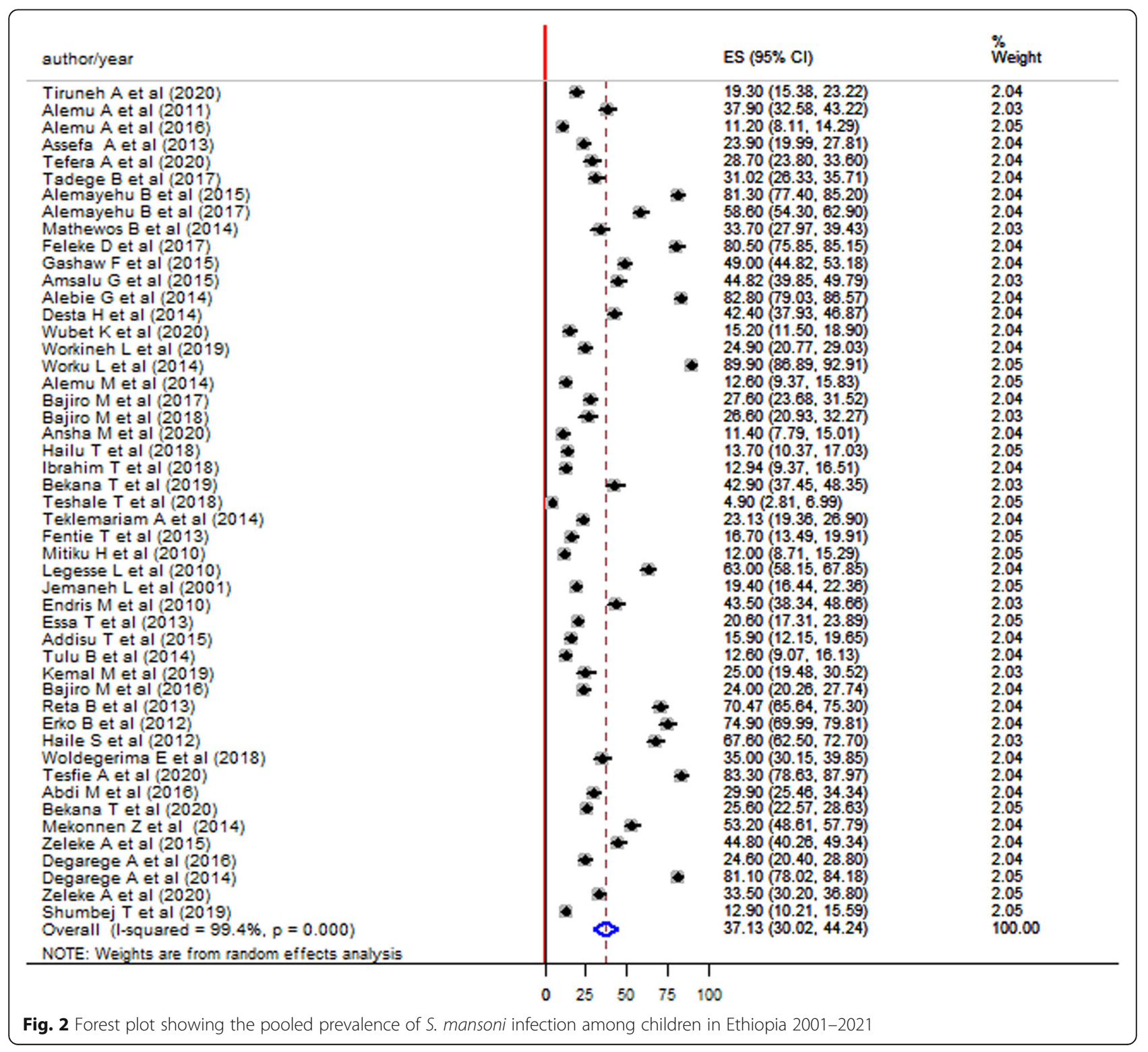




\section{Result}

\section{Selection and identification of studies}

A total of 746 articles were identified through online searching and reference screening. After the initial screening of the title and abstract of the identified studies, the full text of potentially eligible studies was retrieved for detailed assessment. A total of 674 articles were ineligible and excluded. The remaining 72 articles were assessed in detail. About 24 studies were excluded since they lack variables that must be extracted for analysis leaving 49 potentially eligible studies for the final meta-analysis. Preferred Reporting Items for Systematic Review and Meta-analysis statement (PRISMA checklist 2009) was followed [34] (Fig. 1).

\section{Characteristics of included studies}

Forty-nine studies involving 20,493 children (10,572 male and 9,921 females) were included in this meta-analysis. The age of the study participants ranged from 6 months to 19 years old. The studies were conducted from 2001 to 2021 in five national regional states of Ethiopia. Twenty-five studies were conducted in the Amhara region, 11 studies in the Oromia region, 7 studies in the Southern Nation Nationalities and People Region (SNNPR), 5 studies in the Tigray region, and 1 study in the Somali region of Ethiopia. All the included studies had a cross-sectional design and estimated point prevalence. The sample size of the studies ranged from 233 to 798. The majority of the studies used Kato Katz thick smear as a diagnostic method and one study use circulating cathodic antigen (CCA) test (Table 1).

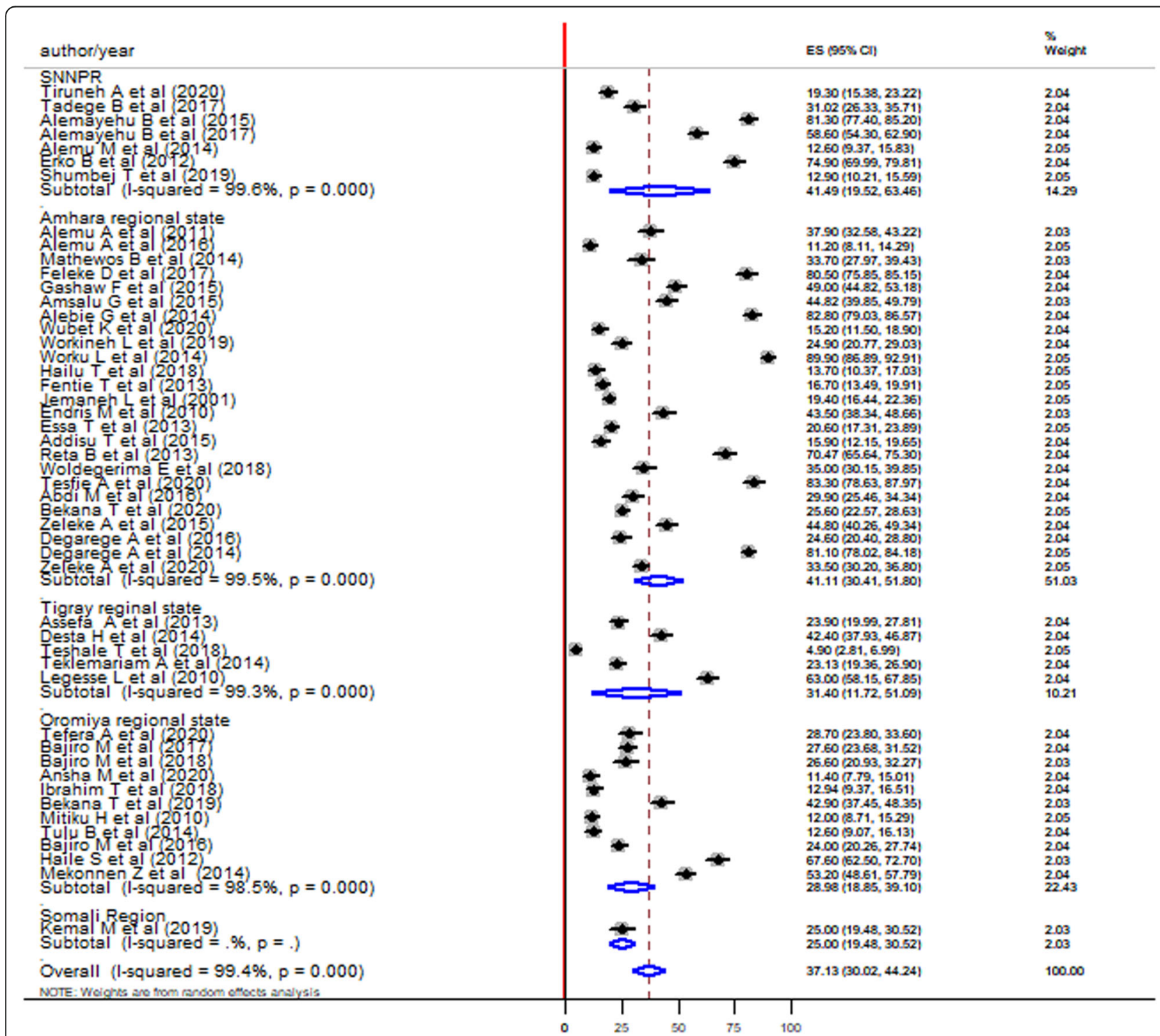

Fig. 3 Forest plot showing the pooled prevalence of S. mansoni infection among children by the regions of Ethiopia 


\section{Prevalence of Schistosoma mansoni among children in} Ethiopia, 2001-2021

The prevalence of $S$. mansoni infection among children in the included studies was ranged from $4.9 \%$ reported in the Tigray region by Teshale T. et al, 2018 [13] to 89.9\% reported from the Amhara region by Worku L. et al 2014 [14]. This meta-analysis and systematic review showed 37.13\% (95\% CI:30.02-44.24) pooled prevalence of $S$. mansoni infection among children using the random effect model. High heterogeneity was observed across the included studies with an $\mathrm{I}^{2}$ value of $99.4 \%, p$ value $<0.000$ (Fig. 2).

\section{Subgroup analysis}

Subgroup analysis was conducted by the region where the studies were conducted, publication year, categorized sample size, and sex. According to the region, the highest pooled prevalence of $S$. mansoni infection among children was in the SNNPR (41.49, 95\%CI: 19.52-63.46) followed by the Amhara region (41.11, 95\%CI: 30.41-51.8), the Tigray region (31.40, 95\%CI: 11.72-51.09) and the Oromia region (28.98, 95\%CI: 18.85-39.10) (Fig. 3).

According to the publication year, the highest pooled prevalence of $S$. mansoni infection was observed in studies conducted from 2011 to 2015 (46.31, 95\%CI:34.21-59.05) followed by 2006 to 2010 (39.46, 95\%CI: $7.58-71.34$ ) and 2016 to 2021 (29.25, 95\%CI: 24.41-38.70) (Fig. 4).

The pooled prevalence was higher among studies that have a sample size of less than or equal to the average sample size $(\leq 419)$ compared to those that have a sample

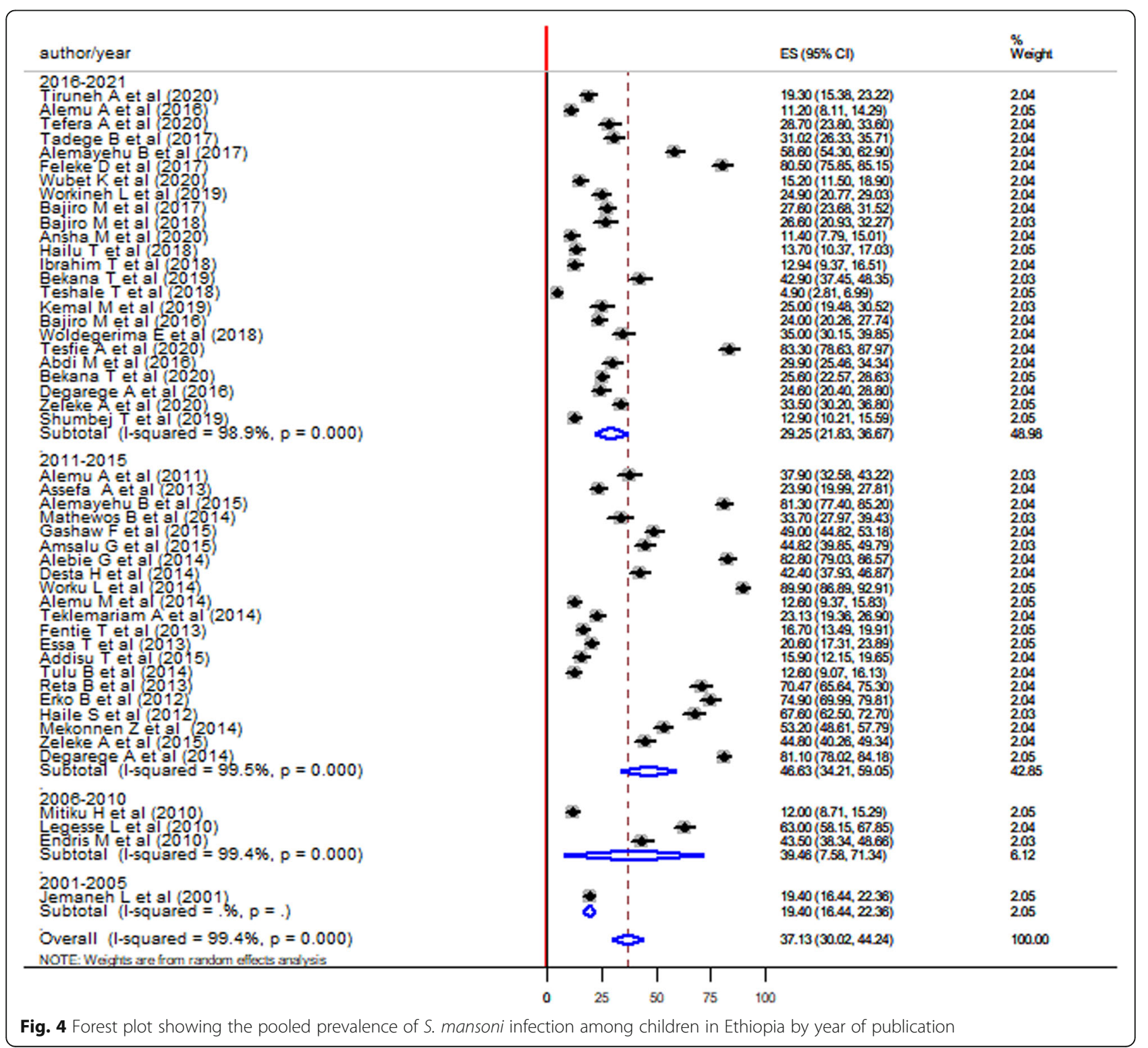


size of greater than the average sample size $(>419)$ (38.71\% vs $34.17 \%)$ (Fig. 5). The pooled prevalence was higher in males (37.51, 95\%CI: 29.99-45.03) (Fig. 6) compared to females (30.36, 95\%CI, 23.36-37.36) (Fig. 7).

\section{Publication bias}

The publication bias was assessed by visual inspection of the funnel plot (Fig. 8) and using egger's test statistics. The logit of proportion and its standard error were used to evaluate the presence or absence of bias. The result showed the absence of publication bias with a $p$-value of 0.320 .

\section{Sensitivity analysis}

Sensitivity analysis was done to check the impact of a single study on pooled prevalence. All the studies were omitted sequentially and the pooled effect size in all cases was within the $95 \%$ confidence interval of the combined effect size. This indicates the absence of a single study impact on the pooled effect size (Table 2).

\section{Discussion}

Schistosoma mansoni infection continues to be a major public health problem worldwide with 240 million cases [2]. To our knowledge, this study is the first comprehensive systematic review and meta-analysis of primary studies to indicate the prevalence of $S$. mansoni infection among children at the national level. We performed compressive reviews and meta-analyses of 49 crosssectional studies reporting the prevalence of $S$. mansoni infection among children in Ethiopia. Ethiopia is continuously implementing the MDA program with large-

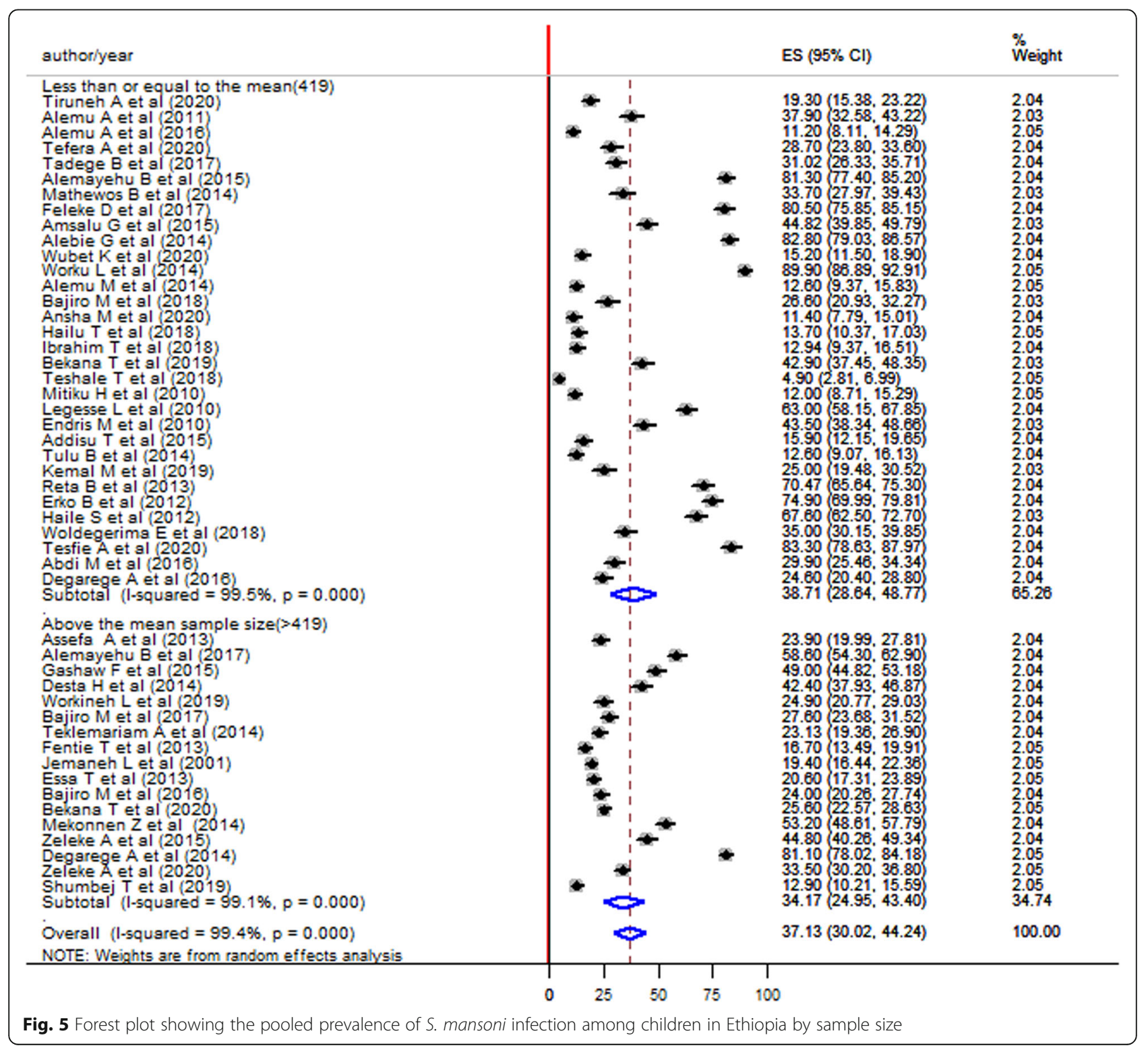




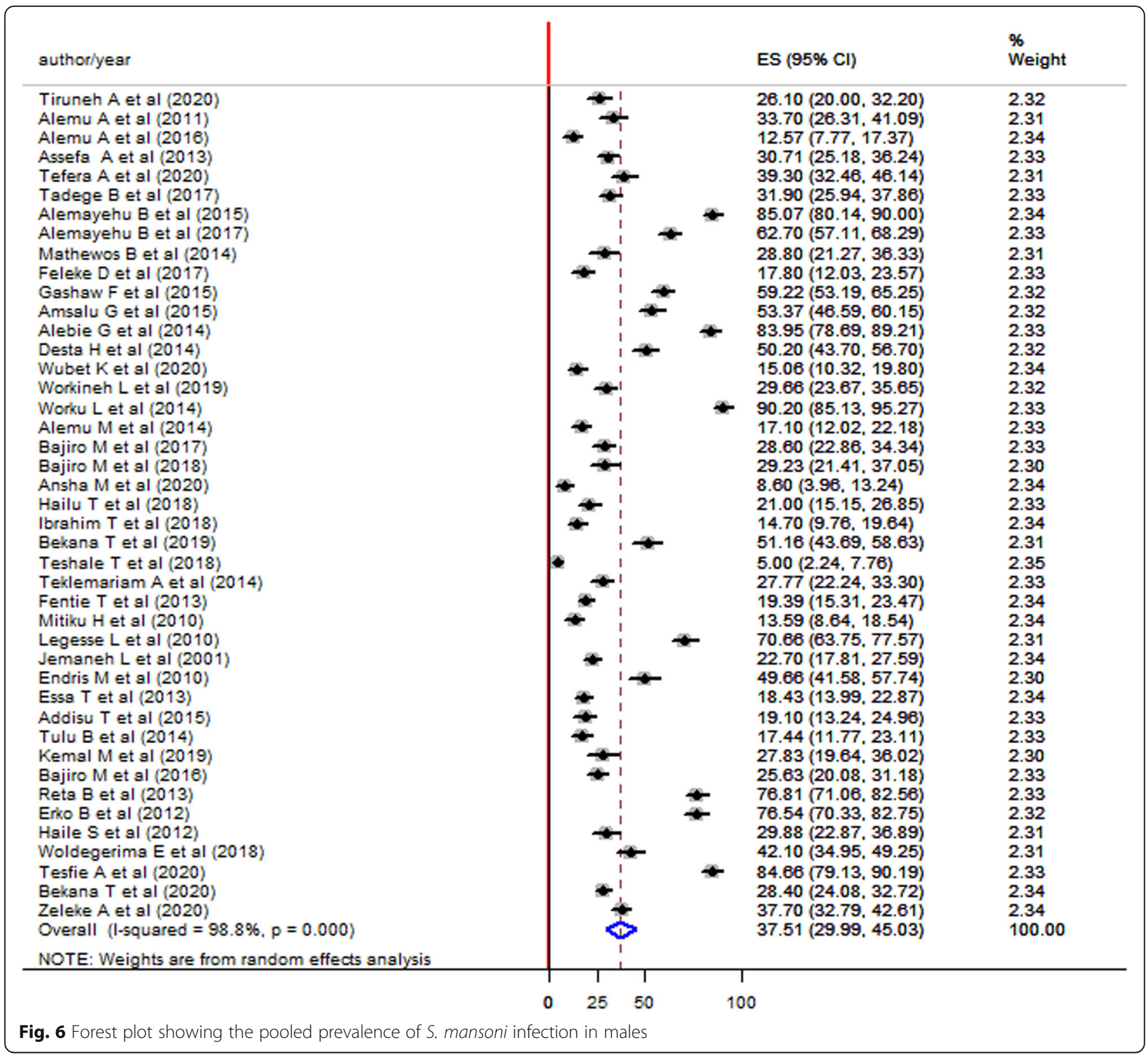

scale periodic treatment since 2010 to reduce the burden of Schistosomiasis and other intestinal parasitic infections. The country has also planned to reduce the national prevalence of Schistosomiasis below $1 \%$ [16].

This systematic review and meta-analysis showed the pooled prevalence of $S$. mansoni infection among children as $37.13 \%$ (95\%CI: 30.02-44.24). This result indicates as Schistosomiasis is still a major public health problem among children in Ethiopia. This finding was higher than the previous meta-analysis conducted in Ethiopia by Hussen et al., and Woldeyohannes et al. that reported 10.9 and $28.78 \%$ pooled prevalence of $S$. mansoni among children respectively [11, 12]. It was also higher than the reports from Mozambique (8.7\%) by Augusto et al., Sierra Leone (16.3, 18.4\%) by Sesay et al.,
Koroma et al., Zimbabwe (7.2\%) by Midzi et al., and Uganda (25.6\%) by Exum et al. [74-78]. The difference might be due to geographical and ecological variation, the difference in implementation of the Schistosomiasis control programs, the difference in the sample size, and the difference in diagnostic methods. The difference in safe water supply and sanitation practices in schools might also have a role in the variability of the prevalence since they do have a vital role in the reduction of Schistosomiasis [79]. The habit of open field defecation and the use of untreated night soil as fertilizer can also increase the transmission of Schistosomiasis [78].

High between-study heterogeneity was noted with an $\mathrm{I}^{2}$ value of $99.4 \%$. To account for this heterogeneity, subgroup analysis was done according to sex, sample size, 


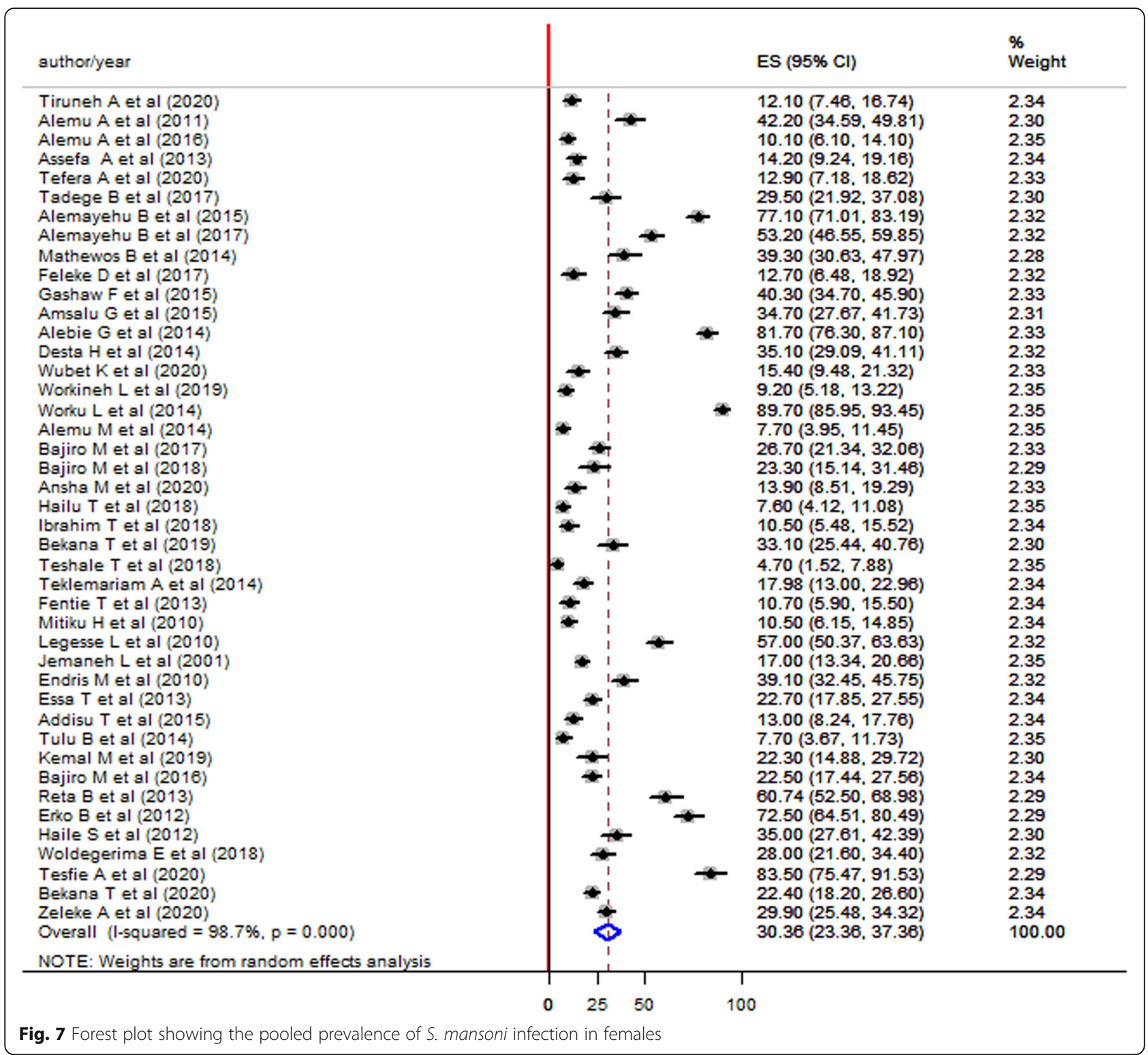

year of publication, and regions where the studies were conducted. However, the heterogeneity remains high after subgroup analysis.

According to subgroup analysis, the pooled prevalence of $S$. mansoni infection was found to be higher among males than females $(37.51 \%$ vs $30.36 \%)$. This was supported by previous studies in Ethiopia that reported being male is $58.3 \%$ more likely to be infected with Schistosomiasis than females and in Brazil [12, 80]. The high prevalence in males might be due to bathing in open freshwater bodies of males than females, outdoor activities of male children in rural areas than females, and engagement of males in irrigation and agricultural activities [58].

The pooled prevalence of $S$. mansoni infection among children was highest in the SNNPR 41.49\% (95\%CI:
19.52-63.46) followed by the Amhara region 41.11\%, (95\%CI: 30.41-51.80), the Tigray region $31.4 \%$, (95\%CI: $11.72-51.09)$, and the Oromia regional state $28.98 \%$, (95\%CI: 18.85-39.10). This variation might be due to the different environmental and ecological variations, the difference in population density, and variability in efficacy of praziquantel [81-83]. The difference in environmental sanitation, personal hygiene, altitude differences, sanitation of streams/rivers, ponds, epidemiology of the snail vector, habit of open defecation, utilization of night soil as a fertilized might also contribute to the difference [84]. The other explanation is that the SNNPR is rich in water bodies which can be favorable for the intermediate snail species.

The current prevalence in the Amhara region (41.11\%) is higher than previous studies that reported the regional 


\section{Funnel plot with pseudo $95 \%$ confidence limits}

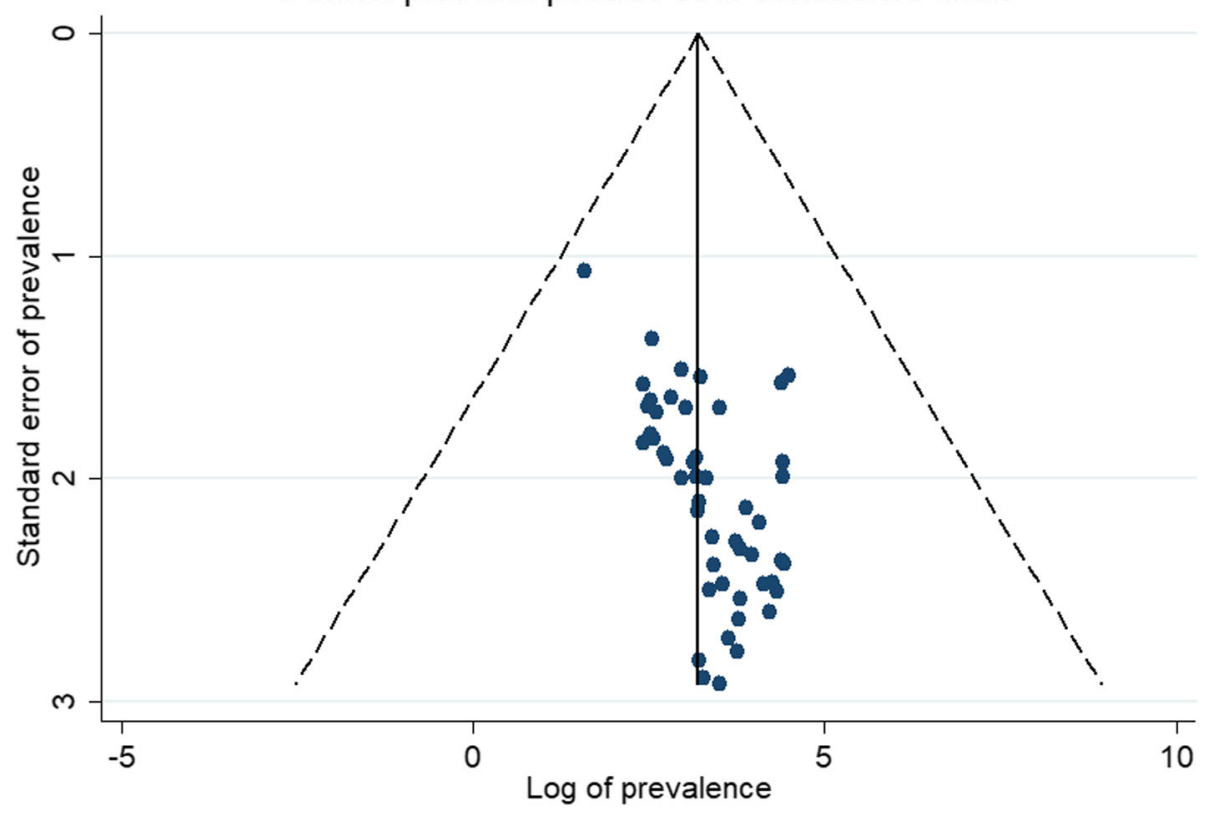

Fig. 8 Funnel plot

prevalence of S. mansoni as 6.9 and $2.6 \%[15,16]$. The variation might be due to differences in sample size, diagnostic methods, and different levels of endemicity in Schistosomiasis. Most of the studies included in this meta-analysis are conducted in Schistosomiasis endemic areas while the previous studies included children from different schools in the region irrespective of endemicity of Schistosomiasis.

The pooled prevalence was found to be high in studies conducted 2011 to 2015 (44.46, 95\%: CI: 30.88-58.03) followed by 2006 to 2010 (39.46, 95\%CI: 7.58-71.34) and 2016 to 2020 (32.09 95\%CI: 22.84-41.34). The reduced prevalence from 2016 to 2020 might be due to the beginning of the mass drug administration (MDA) program in Ethiopia by 2015 [85]. Implementation, monitoring, and evaluation of the Schistosomiasis and Soil-transmitted helminths control program such as mass drug administration program in school [9]. One national survey conducted in 2019 had reported 75.5\% coverage of Praziquantel (PZQ) treatment against school children, this might play a role in the reduction of $S$. mansoni prevalence among school-age children in 2016-2021 [49].

The studies were grouped as studies having above and below the average sample size (the average sample size was 419$)$. The pooled prevalence was $43.93 \%$, (95\%CI: 32.47-55.40) in studies with a sample size of $\leq 419$ and 27.01\% (95\%CI: 20.47-33.56) in studies with sample size $>419$. The between studies heterogeneity remained high even after subgroups analysis.
The symmetry of the funnel plot and the statistical analysis with the egger's test statistics ruled out the absence of publication bias with a $p$-value of 0.320 .

Our study has limitations such as; between-study heterogeneity among enrolled studies was high which might be due to variations in study designs, methodologies, sample populations, and methods of diagnosis employed by the various studies. Only articles published in English were included in the meta-analysis. We did not review the factors that are associated with the prevalence of $S$. mansoni infection. The studies were not evenly distributed across different regions of Ethiopia. The majority of studies included in this systematic review and metaanalysis used Kato-Katz diagnostic method, which is less sensitive than circulating cathodic antigen (CCA), and polymerase chain reaction (PCR). The Kato-Katz test is less sensitive and the egg can be missed due to different reasons like the presence of the egg in the unexamined part of the stool and excretion of the egg by another day this leads to underestimation of the prevalence of $S$. mansoni infection [50].

\section{Conclusion and recommendation}

This systematic review and meta-analysis summarized the high prevalence of $S$. mansoni infection among children in Ethiopia. This shows that $S$. mansoni is still a major public health problem in Ethiopia. The pooled prevalence of $S$. mansoni infection is highest in the SNNPR. Males were more affected than females. This systematic review and meta-analysis identified a wide 
Table 2 Sensitivity analysis

\begin{tabular}{|c|c|c|}
\hline Study omitted & Estimate & $\begin{array}{l}\text { 95\% Confidence } \\
\text { interval }\end{array}$ \\
\hline Tiruneh A et al (2020) [51] & 37.50 & $30.27-44.74$ \\
\hline Alemu A et al (2011) [22] & 37.12 & $29.89-44.34$ \\
\hline Alemu A et al (2016) [52] & 37.67 & $30.46-44.88$ \\
\hline Assefa A et al (2013) [23] & 37.41 & $30.16-44.65$ \\
\hline Tefera A et al (2020) [18] & 37.31 & $30.08-44.54$ \\
\hline Tadege B et al (2017) [35] & 37.26 & $30.02-44.49$ \\
\hline Alemayehu B et al (2015) & 36.21 & $29.23-43.19$ \\
\hline Alemayehu B et al (2017) [36] & 36.68 & $29.50-43.87$ \\
\hline Mathewos B et al (2014) [37] & 37.20 & $29.99-44.42$ \\
\hline Feleke D et al (2017) [39] & 36.23 & $29.18-43.28$ \\
\hline Gashaw F et al (2015) [28] & 36.88 & $29.66-44.11$ \\
\hline Amsalu G et al (2015) [27] & 36.97 & $29.75-44.19$ \\
\hline Alebie G et al (2014) [26] & 36.18 & $29.23-43.13$ \\
\hline Desta H et al (2014) [40] & 37.02 & $29.79-44.25$ \\
\hline Wubet K et al (2020) [41] & 37.59 & $30.36-44.81$ \\
\hline Workineh L et al (2019) [42] & 37.39 & $30.14-44.63$ \\
\hline Worku L et al (2014) [14] & 36.02 & $29.39-42.66$ \\
\hline Alemu M et al (2014) [43] & 37.64 & $30.42-44.86$ \\
\hline Bajiro M et al (2017) [44] & 37.33 & $30.08-44.58$ \\
\hline Bajiro M et al (2018) [45] & 37.35 & $30.13-44.57$ \\
\hline Ansha M et al (2020) [46] & 37.67 & $30.46-44.87$ \\
\hline Hailu T et al (2018) [25] & 37.62 & $30.4-44.85$ \\
\hline Ibrahim T et al (2018) [19] & 37.64 & $30.42-44.85$ \\
\hline Bekana T et al (2019) [47] & 37.01 & $29.8-44.23$ \\
\hline Teshale T et al (2018) [13] & 37.81 & $30.72-44.89$ \\
\hline Teklemariam A et al (2018) [48] & 37.42 & $30.17-44.67$ \\
\hline Fentie T et al (2013) [63] & 37.56 & $30.31-44.80$ \\
\hline Mitiku H et al (2010) [64] & 37.66 & $30.44-44.87$ \\
\hline Legesse L et al (2010) [65] & 36.59 & $29.43-43.76$ \\
\hline Jemaneh L et al (2001) [66] & 37.50 & $30.23-44.78$ \\
\hline Endris M et al (2010) [67] & 37.0 & $29.78-44.23$ \\
\hline Essa T et al (2013) [68] & 37.48 & $30.22-44.74$ \\
\hline Addisu T et al (2015) [69] & 37.57 & $30.35-44.80$ \\
\hline Tulu B et al (2014) [53] & 37.64 & $30.43-44.86$ \\
\hline Kemal M et al (2019) [70] & 37.38 & $30.17-44.6$ \\
\hline Bajiro M et al (2016) [54] & 37.41 & $30.15-44.66$ \\
\hline Reta B et al (2013) [55] & 36.44 & $29.31-43.56$ \\
\hline Erko B et al (2012) [56] & 36.35 & $29.24-43.45$ \\
\hline Haile S et al (2012) [71] & 36.5 & $29.35-43.64$ \\
\hline Woldegerima E et al (2018) [72] & 37.18 & $29.94-44.41$ \\
\hline Tesfie A et al (2020) [73] & 36.17 & $29.14-43.20$ \\
\hline Abdi M et al (2016) [57] & 37.28 & $30.04-44.52$ \\
\hline Bekana T et al (2020) [58] & 37.37 & $30.1-44.67$ \\
\hline
\end{tabular}

Table 2 Sensitivity analysis (Continued)

\begin{tabular}{lll}
\hline Study omitted & Estimate & $\begin{array}{l}\mathbf{9 5 \%} \text { Confidence } \\
\text { interval }\end{array}$ \\
\hline Mekonnen Z et al (2014) [29] & 36.79 & $29.59-44.01$ \\
Jejaw A et al (2015) [17] & 37.01 & $\mathbf{2 9 . 7 5 - 4 4 . 2 1}$ \\
Degarege A et al (2016) [59] & 37.39 & $30.152-44.63$ \\
Degarege A et al (2014) [60] & 36.21 & $\mathbf{2 9 . 3 6 - 4 3 . 0 6}$ \\
Zeleke A et al (2020) [61] & 37.21 & $\mathbf{2 9 . 9 2 - 4 4 . 4 9}$ \\
Shumbej T et al (2019) [62] & 37.64 & $30.40-44.87$ \\
Combined & $\mathbf{3 7 . 1 3}$ & $\mathbf{3 0 . 0 2 - 4 4 . 2 4}$ \\
\hline
\end{tabular}

range of the prevalence of $S$. mansoni among children in Ethiopia from 2001 to 2021.

Finally, our recommendation to the Ethiopian Federal Ministry of Health is to work with different stakeholders and recognize $S$. mansoni infection as still being a major health problem in the country, mainly among children, design long term Schistosomiasis control programs that should be achieved through the provision of safe drinking water in schools, establishing health education programs in schools and the community about personal hygiene, environmental hygiene, proper disposal of waste, keeping water bodies clean, and establishment of sanitation campaigns in each school and community. In addition, increasing the geographical coverage of MDA and improving the delivery of the drug to the MDA sites are also crucial.

Further studies that more sensitive techniques like CAA, PCR should be conducted in endemic areas to indicated the correct estimate. In addition, studies that assess the efficacy of praziquantel periodically and reinfection rate should be motivated.

\section{Abbreviations \\ CCA: Circulating cathodic antigen; MDA: Mass drug administration; PCR: Polymerase chain reaction; SAC: School age children; SNNPR: Southern Nation Nationalities and People's Region}

\section{Acknowledgments}

The authors of this systematic review and meta-analysis would like to acknowledge all the authors of the included studies and friends who participate in searching for the articles.

\section{Authors' contributions}

HB designed the study and wrote the protocol, did the statistical analysis, conceived the study, wrote the first draft and revised subsequent draft of the paper. YE did the electronic search of articles, extract data, and reviewed the first draft. TE did the statistical analysis, extract data, and reviewed the manuscript. All authors read and approved the final manuscript.

\section{Funding}

There is no specific funding for this systematic review and meta-analysis. 


\section{Declarations}

\section{Ethical approval and consent to participate}

Since this study is a systematic review and meta-analysis and does not involve human and animal studies, Ethical approval and consent to participate are not applicable.

\section{Consent for publication}

Not applicable.

\section{Competing interests}

The authors declared no competing interests.

\section{Author details}

College of Medicine and Health Sciences, Department of Medical Laboratory Sciences, Wollo University, Dessie, Ethiopia. ${ }^{2}$ College of Medicine and Health Sciences, School of Biomedical and Laboratory Sciences, Department of Medical Parasitology, University of Gondar, Gondar, Ethiopia.

\section{Received: 11 March 2021 Accepted: 7 September 2021}

\section{Published online: 01 December 2021}

\section{References}

1. Mackey TK, Liang BA, Cuomo R, Hafen R, Brouwer KC, Lee DE. Emerging and reemerging neglected tropical diseases: a review of key characteristics, risk factors, and the policy and innovation environment. Clin Microbiol Rev. 2014;27(4):949-79. https://doi.org/10.1128/CMR.00045-14.

2. Ross AGP, Chau TN, Inobaya MT, Olveda RM, Li Y, Harn DA. A new global strategy for the elimination of schistosomiasis. Int J Infect Dis. 2017;54:1307. https://doi.org/10.1016/j.ijid.2016.09.023.

3. Adenowo AF, Oyinloye BE, Ogunyinka BI, Kappo AP. Impact of human schistosomiasis in sub-Saharan Africa. Braz J Infect Dis. 2015;19(2):196-205. https://doi.org/10.1016/j.bjid.2014.11.004

4. Colley DG, Bustinduy AL, Secor WE, King CH. Human schistosomiasis. Lancet. 2014:383(9936):2253-64. https://doi.org/10.1016/S0140-6736(13)61949-2.

5. Savioli L, Albonico M, Colley DG, Correa-Oliveira R, Fenwick A, Green W, et al. Building a global schistosomiasis alliance: an opportunity to join forces to fight inequality and rural poverty. Infect Dis Poverty. 2017;6(1):65-70. https://doi.org/10.1186/s40249-017-0280-8.

6. Fenwick A, Webster JP, Bosque-Oliva E, Blair L, Fleming FM, Zhang Y, et al. The schistosomiasis control initiative (SCI): rationale, development and implementation from 2002-2008. Parasitology. 2009;136(13):1719-30. https://doi.org/10.1017/S0031182009990400.

7. Savioli L, Gabrielli AF, Montresor A, Chitsulo L, Engels D. Schistosomiasis control in Africa: 8 years after world health assembly resolution 54.19. Parasitology. 2009;136(13):1677-81. https://doi.org/10.1017/S0031182 009991181.

8. WHO. Schistosomiasis: progress report 2001-2011 strategic plan 2012-2020. Geneva: World Health Organization; 2013. p. 9241503173.

9. Negussu N, Mengistu B, Kebede B, Deribe K, Ejigu E, Tadesse G, et al. Ethiopia schistosomiasis and soil-transmitted helminthes control programme: progress and prospects. Ethiop Med J. 2017;55(1):75-80.

10. Deribe K, Meribo K, Gebre T, Hailu A, Ali A, Aseffa A, et al. The burden of neglected tropical diseases in Ethiopia, and opportunities for integrated control and elimination. Parasit Vectors. 2012;5(1):240. https://doi.org/10.11 86/1756-3305-5-240

11. Hussen S, Assegu D, Shimelis T. Prevalence of Schistosoma mansoni infection in Ethiopia: a systematic review and meta-analysis. Microbiology. 2019;7:4.

12. Woldeyohannes D, Sahiledengle B, Tekalegn Y, Hailemariam Z. Prevalence of Schistosomiasis (S. mansoni and S. haematobium) and its association with gender of school age children in Ethiopia: a systematic review and meta-analysis. Parasite Epidemiol Control. 2021;13:e00210.

13. Teshale T, Belay S, Tadesse D, Awala A, Teklay G. Prevalence of intestinal helminths and associated factors among school children of Medebay Zana wereda; North Western Tigray, Ethiopia 2017. BMC Res Notes. 2018;11(1):444. https://doi.org/10.1186/s13104-018-3556-6.

14. Worku L, Damte D, Endris M, Tesfa H, Aemero M. Schistosoma mansoni infection and associated determinant factors among school children in Sanja town, Northwest Ethiopia. J Parasitol Res. 2014;2014:1-7. https://doi. org/10.1155/2014/792536.
15. Nute AW, Endeshaw T, Stewart AEP, Sata E, Bayissasse B, Zerihun M, et al. Prevalence of soil-transmitted helminths and Schistosoma mansoni among a population-based sample of school-age children in Amhara region, Ethiopia. Parasit Vectors. 2018;11(1):431. https://doi.org/10.1186/s13071-01 8-3008-0.

16. Leta GT, French M, Dorny P, Vercruysse J, Levecke B. Comparison of individual and pooled diagnostic examination strategies during the national mapping of soil-transmitted helminths and Schistosoma mansoni in Ethiopia. PLoS Negl Trop Dis. 2018;12(9):e0006723.

17. Jejaw A, Zemene E, Alemu Y, Mengistie Z. High prevalence of Schistosoma mansoni and other intestinal parasites among elementary school children in Southwest Ethiopia: a cross-sectional study. BMC Public Health. 2015;15(1): 600. https://doi.org/10.1186/s12889-015-1952-6.

18. Tefera A, Belay T, Bajiro M. Epidemiology of Schistosoma mansoni infection and associated risk factors among school children attending primary schools nearby rivers in Jimma town, an urban setting, Southwest Ethiopia. PLoS ONE. 2020;15(2):e0228007. https://doi.org/10.1371/journal.pone.022 8007

19. Ibrahim T, Zemene E, Asres $Y$, Seyoum D, Tiruneh A, Gedefaw L, et al. Epidemiology of soil-transmitted helminths and Schistosoma mansoni: a base-line survey among school children, Ejaji, Ethiopia. J Infect Dev Ctries. 2018;12(12):1134-44. https://doi.org/10.3855/jidc.9665.

20. Afework Bitew A, Abera B, Seyoum W, Endale B, Kiber T, Goshu G, et al. Soiltransmitted helminths and Schistosoma mansoni infections in Ethiopian orthodox church students around Lake Tana, Northwest Ethiopia. PLoS ONE. 2016;11(5):e0155915. https://doi.org/10.1371/journal.pone.0155915.

21. Gebreyohanns A, Legese MH, Wolde M, Leta G, Tasew G. Prevalence of intestinal parasites versus knowledge, attitude and practices (KAPs) with special emphasis to Schistosoma mansoni among individuals who have river water contact in Addiremets town, Western Tigray, Ethiopia. PLoS ONE. 2018;13(9):e0204259. https://doi.org/10.1371/journal.pone.0204259.

22. Alemu A, Atnafu A, Addis Z, Shiferaw Y, Teklu T, Mathewos B, et al. Soil transmitted helminths and Schistosoma mansoni infections among school children in zarima town, Northwest Ethiopia. BMC Infect Dis. 2011;11(1):189. https://doi.org/10.1186/1471-2334-11-189.

23. Assefa A, Dejenie T, Tomass Z. Infection prevalence of Schistosoma mansoni and associated risk factors among school children in suburbs of Mekelle city, Tigray, northern Ethiopia. Momona Ethiop J Sci. 2013;5(1):174-88. https://doi.org/10.4314/mejs.v5i1.85339.

24. Abebe N, Erko B, Medhin G, Berhe N. Clinico-epidemiological study of schistosomiasis mansoni in Waja-Timuga, district of Alamata, northern Ethiopia. Parasit Vectors. 2014;7(1):158. https://doi.org/10.1186/1756-3305-7-1 58.

25. Hailu T, Alemu M, Abera B, Mulu W, Yizengaw E, Genanew A, et al. Multivariate analysis of factors associated with Schistosoma mansoni and hookworm infection among primary school children in rural Bahir Dar, Northwest Ethiopia. Trop Dis Travel Med Vaccines. 2018;4(1):4. https://doi. org/10.1186/s40794-018-0064-6.

26. Alebie G, Erko B, Aemero M, Petros B. Epidemiological study on Schistosoma mansoni infection in Sanja area, Amhara region, Ethiopia. Parasit Vectors. 2014;7(1):15. https://doi.org/10.1186/1756-3305-7-15.

27. Amsalu G, Mekonnen Z, Erko B. A new focus of schistosomiasis mansoni in Hayk town, northeastern Ethiopia. BMC Res Notes. 2015;8(1):22. https://doi. org/10.1186/s13104-014-0965-z.

28. Gashaw F, Aemero M, Legesse M, Petros B, Teklehaimanot T, Medhin G, et al. Prevalence of intestinal helminth infection among school children in Maksegnit and Enfranz towns, northwestern Ethiopia, with emphasis on Schistosoma mansoni infection. Parasit Vectors. 2015;8(1):567. https://doi. org/10.1186/s13071-015-1178-6.

29. Mekonnen Z, Meka S, Zeynudin A, Suleman S. Schistosoma mansoni infection and undernutrition among school age children in Fincha'a sugar estate, rural part of West Ethiopia. BMC Res Notes. 2014;7(1):763. https://doi. org/10.1186/1756-0500-7-763.

30. Leta GT, Mekete K, Wuletaw Y, Gebretsadik A, Sime H, Mekasha S, et al. National mapping of soil-transmitted helminth and schistosome infections in Ethiopia. Parasit Vectors. 2020;13(1):437. https://doi.org/10.1186/s13071-02 0-04317-6.

31. Munn Z, Moola S, Lisy K, Riitano D, Tufanaru C. Methodological guidance for systematic reviews of observational epidemiological studies reporting prevalence and cumulative incidence data. JBI Evid Implementation. 2015; 13(3):147-53. 
32. Higgins JPT, Thompson SG. Quantifying heterogeneity in a meta-analysis. Stat Med. 2002;21(11):1539-58. https://doi.org/10.1002/sim.1186.

33. Tang J-L, Liu JL. Misleading funnel plot for detection of bias in metaanalysis. J Clin Epidemiol. 2000;53(5):477-84. https://doi.org/10.1016/ S0895-4356(99)00204-8.

34. Moher D, Liberati A, Tetzlaff J, Altman DG, PRISMA Group. Preferred reporting items for systematic reviews and meta-analyses: the PRISMA statement. Ann Intern Med. 2009;151(4):264-9, W64. https://doi.org/10.7326/ 0003-4819-151-4-200908180-00135

35. Tadege B, Shimelis T. Infections with Schistosoma mansoni and geohelminths among school children dwelling along the shore of the Lake Hawassa, southern Ethiopia. PLoS One. 2017;12(7):e0181547. https://doi. org/10.1371/journal.pone.0181547.

36. Alemayehu B, Tomass Z. Schistosoma mansoni infection prevalence and associated risk factors among schoolchildren in Demba Girara, Damot Woide District of Wolaita zone, southern Ethiopia. Asian Pac J Trop Med 2015;8(6):457-63. https://doi.org/10.1016/j.apjtm.2015.05.009.

37. Alemayehu B, Tomass Z, Wadilo F, Leja D, Liang S, Erko B. Epidemiology of intestinal helminthiasis among school children with emphasis on Schistosoma mansoni infection in Wolaita zone, Southern Ethiopia. BMC Public Health. 2017;17(1):587. https://doi.org/10.1186/s12889-017-4499-x.

38. Mathewos B, Alemu A, Woldeyohannes D, Alemu A, Addis Z, Tiruneh M, et al. Current status of soil transmitted helminths and Schistosoma mansoni infection among children in two primary schools in North Gondar, Northwest Ethiopia: a cross sectional study. BMC Res Notes. 2014;7(1):88. https://doi.org/10.1186/1756-0500-7-88.

39. Feleke DG, Arega S, Tekleweini M, Kindie K, Gedefie A. Schistosoma mansoni and other helminthes infections at Haike primary school children, northeast, Ethiopia: a cross-sectional study. BMC Res Notes. 2017;10(1):609. https://doi.org/10.1186/s13104-017-2942-9.

40. Desta H, Bugssa G. The current status of Schistosoma mansoni infection among school children around Hizaty Wedicheber Microdam in Merebmieti, Ethiopia. J Bacteriol Parasitol. 2014;5(5):204-10.

41. Wubet K, Damtie D. Prevalence of Schistosoma mansoni infection and associated risk factors among school children in Jiga town, northwestEthiopia: a cross-sectional study. J Parasitol Res. 2020:1-7.

42. Workineh L, Yimer M, Gelaye W, Muleta D. The magnitude of Schistosoma mansoni and its associated risk factors among Sebatamit primary school children, rural Bahir Dar, Northwest Ethiopia: a cross-sectional study. BMC Res Notes. 2019;12(1):447. https://doi.org/10.1186/s13104-019-4498-3.

43. Alemu M. Prevalence of intestinal schistosomiasis and soil-transmitted helminthiasis among primary school children in Umolante District, South Ethiopia. Clin Microbiol Rev. 2014;3(6):174. https://doi.org/10.11648/j.cmr.2 0140306.14.

44. Bajiro M, Dana D, Levecke B. Prevalence and intensity of Schistosoma mansoni infections among schoolchildren attending primary schools in an urban setting in Southwest, Ethiopia. BMC Res Notes. 2017;10(1):677. 9.

45. Bajiro M, Gedamu S, Hamba N, Alemu Y. Prevalence, intensity of infection and associated risk factors for Schistosoma mansoni and soil transmitted helminthes among two primary school children at nearby Rivers in Jimma town, south West Ethiopia. Ann Clin Pathol. 2018;6(4):1144-51.

46. Ansha MG, Kuti KA, Girma E. Prevalence of intestinal schistosomiasis and associated factors among school children in Wondo District, Ethiopia. J Trop Med. 2020;2020:1-8. https://doi.org/10.1155/2020/9813743.

47. Bekana T, Hu W, Liang S, Erko B. Transmission of Schistosoma mansoni in Yachi areas, southwestern Ethiopia: new foci. Infect Dis Poverty. 2019;8(1):1. https://doi.org/10.1186/s40249-018-0513-5.

48. Teklemariam D, Legesse M, Degarege A, Liang S, Erko B. Schistosoma mansoni and other intestinal parasitic infections in schoolchildren and vervet monkeys in Lake Ziway area, Ethiopia. BMC Res Notes. 2018;11(1):146. https://doi.org/10.1186/s13104-018-3248-2

49. Chisha Y, Zerdo Z, Asnakew M, Churko C, Yihune M, Teshome A, et al. Praziquantel treatment coverage among school age children against Schistosomiasis and associated factors in Ethiopia: a cross-sectional survey, 2019. BMC Infect Dis. 2020;20(1):872.

50. Colley DG, King CH, Kittur N, Ramzy RMR, Secor WE, Fredericks-James M, et al. Evaluation, validation, and recognition of the point-of-care circulating cathodic antigen, urine-based assay for mapping Schistosoma mansoni infections. J Trop Med Hyg. 2020;103:42-9.

51. Tiruneh A, Kahase D, Zemene E, Tekalign E, Solomon A, Mekonnen Z. Identification of transmission foci of Schistosoma mansoni: narrowing the intervention target from district to transmission focus in Ethiopia. BMC Public Health. 2020;20(1):769. https://doi.org/10.1186/s12889-02008904-1.

52. Alemu A, Tegegne Y, Damte D, Melku M. Schistosoma mansoni and soiltransmitted helminths among preschool-aged children in Chuahit, Dembia district, Northwest Ethiopia: prevalence, intensity of infection and associated risk factors. BMC Public Health. 2016;16(1):422. https://doi.org/10.1186/s12 889-016-2864-9.

53. Tulu B, Taye S, Amsalu E. Prevalence and its associated risk factors of intestinal parasitic infections among Yadot primary school children of south eastern Ethiopia: a cross-sectional study. BMC Res Notes. 2014; 7(1):848-54. https://doi.org/10.1186/1756-0500-7-848.

54. Bajiro M, Dana D, Ayana M, Emana D, Mekonnen Z, Zawdie B, et al. Prevalence of Schistosoma mansoni infection and the therapeutic efficacy of praziquantel among school children in Manna District, Jimma zone, Southwest Ethiopia. Parasit Vectors. 2016;9(1):560. https://doi.org/10.1186/ s13071-016-1833-6.

55. Reta B, Erko B. Efficacy and side effects of praziquantel in the treatment for Schistosoma mansoni infection in school children in Senbete town, northeastern Ethiopia. Tropical Med Int Health. 2013;18(11):1338-43. https:// doi.org/10.1111/tmi.12187.

56. Erko B, Degarege A, Tadesse K, Mathiwos A, Legesse M. Efficacy and side effects of praziquantel in the treatment of schistosomiasis mansoni in schoolchildren in Shesha Kekele Elementary School, Wondo Genet, Southern Ethiopia. Asian Pac J Trop Biomed. 2012;2(3):235-9. https://doi. org/10.1016/\$2221-1691(12)60049-5.

57. Abdi M, Nibret E, Munshea A. Prevalence of intestinal helminthic infections and malnutrition among schoolchildren of the Zegie peninsula, northwestern Ethiopia. J Infect Public Health. 2017;10(1):84-92. https://doi. org/10.1016/j.jiph.2016.02.009.

58. Bekana T, Berhe N, Eguale T, Aemero M, Medhin G, Tulu B, et al. Prevalence and factors associated with intestinal schistosomiasis and human fascioliasis among school children in Amhara regional state, Ethiopia. Trop Med Health. 2021;49(1):35. https://doi.org/10.1186/s41182-021-00326-y.

59. Degarege A, Yimam Y, Madhivanan P, Erko B. The relationship between helminth infections and low haemoglobin levels in Ethiopian children with blood type a. J Helminthol. 2016;91(3):278-83. https://doi.org/10.1017/ S0022149X16000286.

60. Degarege A, Legesse M, Medhin G, Teklehaymanot T, Erko B. Day-today fluctuation of point-of-care circulating cathodic antigen test scores and faecal egg counts in children infected with Schistosoma mansoniin Ethiopia. BMC Infect Dis. 2014;14(1):210. https://doi.org/10.1186/14 71-2334-14-210.

61. Zeleke AJ, Addisu A, Tegegne Y. Prevalence, Intensity, and Associated Factors of Schistosoma mansoni among School Children in Northwest Ethiopia. Gonz lez Salazar F, editor. J Parasitol Res. 2020:1-7.

62. Shumbej T, Menu S, Girum T, Bekele F, Gebru T, Worku M, et al. Impact of annual preventive mass chemotherapy for soil-transmitted helminths among primary school children in an endemic area of Gurage zone: a prospective cross-sectional study. Res Rep Trop Med. 2019;10:109-18. https://doi.org/10.2147/RRTM.S208473.

63. Fentie T, Erqou S, Gedefaw M, Desta A. Epidemiology of human fascioliasis and intestinal parasitosis among school children in Lake Tana Basin, northwest Ethiopia. Trans Royal Soc Trop Med Hyg. 2013;107(8):480-6. https://doi.org/10.1093/trstmh/trt056.

64. Mitiku H, Legesse M, Teklemariam Z, Erko B. Transmission of Schistosoma mansoni in Tikur Wuha area, Southern Ethiopia. Ethiop J Heal Dev. 2010; 24(3):180-4. https://doi.org/10.4314/ejhd.v24i3.68382.

65. Legesse L, Erko B, Hailu A. Current status of intestinal schistosomiasis and soiltransmitted helminthiasis among primary school children in Adwa town, Northern Ethiopia. Ethiop J Heal Dev. 2010;24(3):191-7. https://doi.org/1 0.4314/ejhd.v24i3.68384.

66. Jemaneh L. Soil-transmitted helminth infections and schistosomiasis mansoni in school children from Chilga District, Northwest Ethiopia. Ethiop J Health Sci. 2001;11(2):79-87.

67. Endris M, Lemma W, Belyhun Y, Moges B, Gelaw A, Anagaw B, et al. Prevalence of intestinal parasites and associated risk factors among students of Atse-fasil general elementary school Azezo, Northwest Ethiopia. Ethiop J Health Biomed Sci. 2010;3(1):25-33.

68. Essa T, Birhane Y, Endris M, Moges A, Moges F. Current status of Schistosoma mansoni infections and associated risk factors among students 
in Gorgora town, Northwest Ethiopia. ISRN Infect Dis. 2013;2013:1-7. https:// doi.org/10.5402/2013/636103.

69. Addisu T, Asmamaw A. A survey of soil-transmitted helminths infections and schistosomiasis mansoni among school children in Libo-Kemkem District, Northwest Ethiopia: cross sectional study. Am J Health Res. 2015; 3(2):57-62. https://doi.org/10.11648/j.ajhr.20150302.12.

70. Kemal M, Tadesse G, Esmael A, Abay SM, Kebede T. Schistosoma mansoni infection among preschool age children attending Erer health center, Ethiopia and the response rate to praziquantel. BMC Res Notes. 2019;12(1): 211. https://doi.org/10.1186/s13104-019-4246-8.

71. Haile S, Golassa L, Mekonnen Z. Prevalence of Schistosoma mansoni and effectiveness of Praziquantel in school children in Finchaa valley, Ethiopia. J Parasitol Vector Biol. 2012;4(3):25-30.

72. Woldegerima E, Bayih AG, Tegegne $Y$, Aemero M, Jejaw ZA. Prevalence and reinfection rates of Schistosoma mansoni and praziquantel efficacy against the parasite among primary school children in Sanja town, Northwest Ethiopia. J Parasitol Res. 2019;2019:1-8. https://doi.org/10.11 55/2019/3697216

73. Tesfie A, Getnet G, Abere A, Yihenew G, Belete Y, Kassa M, et al. Praziquantel is an effective drug for the treatment of Schistosoma Mansoni infection among school-aged children in Northwest Ethiopia. Trop Med Health. 2020; 48(1):28. https://doi.org/10.1186/s41182-020-00204-z.

74. Sabonete A, Augusto G, Nalá R, Mapaco L, Casmo V, Monteiro J. Geographic distribution and prevalence of schistosomiasis and soil-transmitted helminths among schoolchildren in Mozambique. Am J Trop Med Hyg. 2009;81(5):799-803. https://doi.org/10.4269/ajtmh.2009.08-0344.

75. Sesay S, Paye J, Bah MS, McCarthy F, Conteh A, Sonnie M, et al. Schistosoma mansoni infection after three years of mass drug administration in Sierra Leone. Parasit Vectors. 2014;7(1):14. https://doi.org/10.1186/1756-3305-7-14.

76. Koroma JB, Peterson J, Gbakima AA, Nylander FE, Sahr F, Soares Magalhães RJ, et al. Geographical distribution of intestinal schistosomiasis and soiltransmitted helminthiasis and preventive chemotherapy strategies in Sierra Leone. PLoS Negl Trop Dis. 2010;4(11):e891. https://doi.org/10.1371/journal. pntd.0000891.

77. Midzi N, Mduluza T, Chimbari MJ, Tshuma C, Charimari L, Mhlanga G, et al. Distribution of schistosomiasis and soil transmitted helminthiasis in Zimbabwe: towards a national plan of action for control and elimination. PLoS Negl Trop Dis. 2014;8(8):e3014. https://doi.org/10.1371/journal.pntd. 0003014.

78. Exum NG, Kibira SPS, Ssenyonga R, Nobili J, Shannon AK, Ssempebwa JC, et al. The prevalence of schistosomiasis in Uganda: a nationally representative population estimate to inform control programs and water and sanitation interventions. PLoS Negl Trop Dis. 2019;13(8):e0007617. https://doi.org/10.1371/journal.pntd.0007617.

79. Grimes JET, Croll D, Harrison WE, Utzinger J, Freeman MC, Templeton MR. The relationship between water, sanitation and schistosomiasis: a systematic review and meta-analysis. PLoS Negl Trop Dis. 2014;8(12):e3296. https://doi. org/10.1371/journal.pntd.0003296.

80. Calasans TAS, Souza GTR, Melo CM, Madi RR, de Lourdes Sierpe Jeraldo V. Socioenvironmental factors associated with Schistosoma mansoni infection and intermediate hosts in an urban area of northeastern Brazil. PLoS ONE. 2018;13(5):e0195519.

81. Ponpetch K, Erko B, Bekana T, Richards L, Liang S. Biogeographical characteristics of Schistosoma mansoni endemic areas in Ethiopia: a systematic review and meta analysis. Infect Dis Poverty. 2021;10(1):83. https://doi.org/10.1186/s40249-021-00864-X.

82. Bisetegn $\mathrm{H}$, Erkihun $\mathrm{Y}$. Efficacy of praziquantel treatment for Schistosoma mansoni infection among children in Ethiopia: systematic review and metaanalysis. Int J Immunol. 2020;8(4):61-9.

83. Nagi S, Chadeka EA, Sunahara T, Mutungi F, Dan Justin YK, Kaneko S, et al. Risk factors and spatial distribution of Schistosoma mansoni infection among primary school children in Mbita district, western Kenya. PLoS Negl Trop Dis. 2014;8(7):e2991.

84. Mohammed J, Weldegebreal F, Teklemariam Z, Mitiku H. Clinicoepidemiology, malacology and community awareness of Schistosoma mansoni in Haradenaba and Dertoramis kebeles in Bedeno district, eastern Ethiopia. SAGE Open Med. 2018;6:205031211878674. https://doi.org/10.11 77/2050312118786748.

85. Mengitsu B, Shafi O, Kebede B, Kebede F, Worku DT, Herero M, et al. Ethiopia and its steps to mobilize resources to achieve 2020 elimination and control goals for neglected tropical diseases. Int Health. 2016;8(1):i34-52. https://doi.org/10.1093/inthealth/ihw007.

\section{Publisher's Note}

Springer Nature remains neutral with regard to jurisdictional claims in published maps and institutional affiliations.
Ready to submit your research? Choose BMC and benefit from:

- fast, convenient online submission

- thorough peer review by experienced researchers in your field

- rapid publication on acceptance

- support for research data, including large and complex data types

- gold Open Access which fosters wider collaboration and increased citations

- maximum visibility for your research: over $100 \mathrm{M}$ website views per year

At BMC, research is always in progress.

Learn more biomedcentral.com/submissions 